\title{
Risk of Smoking in the Causation of Ischemic Stroke: Experience of 100 Cases in Bangladesh
}

\author{
Nazia Sharmin ${ }^{1}$, Zakiur Rahman ${ }^{2}$, Md. Abdullah Yusuf ${ }^{3}$, Nawazna Rahman ${ }^{4}$ \\ ${ }^{1}$ Department of Biochemistry, Monno Medical College, Manikganj, Bangladesh \\ ${ }^{2}$ Department of Microbiology, Monno Medical College, Manikganj, Bangladesh \\ ${ }^{3}$ Department of Microbiology, National Institute of Neurosciences \& Hospital, Dhaka, Bangladesh \\ ${ }^{4}$ Department of Pathology, Ibrahim Medical College, Dhaka, Bangladesh
}

\section{Email address}

nstanya@gmail.com (N. Sharmin),profzakiur@gmail.com (Z. Rahman), ayusuf75@yahoo.com (Md. A. Yusuf), radioactive.flames@gmail.com (N. Rahman)

\section{To cite this article:}

Nazia Sharmin, Zakiur Rahman, Md. Abdullah Yusuf, Nawazna Rahman. Risk of Smoking in the Causation of Ischemic Stroke: Experience of 100 Cases in Bangladesh. European Journal of Preventive Medicine. Vol. 4, No. 6, 2016, pp. 132-135. doi: 10.11648/j.ejpm.20160406.12

Received: September 6, 2016; Accepted: October 31, 2016; Published: January 13, 2017

\begin{abstract}
Background: Ischemic stroke is more commonly occurs in smokers Objective: The purpose of the present study was to estimate the risk of smoking with ischemic stroke in Bangladesh. Methodology: This case control study was carried out in the Department of Biochemistry at Dhaka Medical College, Dhaka, Bangladesh from January 2014 to December 2014. Thepatients presented with ischemic stroke, age ranges from 18 to 65 years of both sexes were taken as cases. Age and sex matched healthy individuals were selected as controls. History was taken from both cases and controls regarding smoking habit and duration of smoking. Results: Inthis study $42 \%$ of case group and $11 \%$ control group were smoker $(\mathrm{p}=0.032)$ and the mean duration of smoking was $22.14 \pm 10.58$ years and $4.45 \pm 2.58$ years for those groups respectively. The odd ratio (OR) was $2.56(95 \% .0718$ to 6.1501$)$. Conclusions: Smoking is significantly associated with ischemic stroke.
\end{abstract}

Keywords: Stroke, Risk, Smoking

\section{Introduction}

Worldwide ischemic stroke is a major public health problem and a leading cause of mortality and morbidity particularly in developing countries [1]. Stroke predominates in the middle and late years of life and it is ranked after heart disease and before cancer $[2,3]$.

Generally, it is recognized that stroke is a multifactorial condition. A number of risk factors that have been shown to be associated with stroke are age, high blood pressure, diabetes mellitus, hypercholesterolemia, previous history of stroke or, Transient Ischemic Attack (TIA), obesity and dietary factors, atrial fibrillation and cigarette smoking [4].

Smoking is a major modifiable risk factor for atherosclerotic disease [5]. Cigarette smoking increases the risk of ischemic stroke nearly two times; with a clear doseresponse relation [6]. Tobacco smoking is a leading modifiable global disease risk factor. Global agestandardized prevalence of daily tobacco smoking was $31.1 \%$ in 2012 for men [7]. Nearly $80 \%$ of the more than one billion smokers worldwide live in low and middle-income countries, where the burden of smoking related illness and death is heaviest [8]. Bangladesh is a low-income country and one of the largest tobacco consuming countries in the world [7]. According to a previous study of Bangladesh, smoking causes about $25.0 \%$ of all deaths in Bangladeshi men aged 25 to 69 years and an average loss of 7 years of life per smoker [9]. In general, the prevalence of smoking peaks between the ages of 18 to 44 years and decreases dramatically after the age of 65 years; this is directly related to smoking-related illness. In the USA, the prevalence of smoking remains alarmingly high. $20.8 \%$ of the US adult population smokes according to the recent data of CDC. This represents only a $3 \%$ decline in smoking prevalence over the last 10 years. Worldwide, over one billion more cigarettes were consumed in 2000 compared with 1980 [10]. 
Risk of stroke is more in current smoker than the exsmoker. The mechanism by which smoking is thought to increase the likelihood of ischemic stroke include increased fibrinogen level and platelet adhesiveness and reduced cerebral blood flow mainly due to atheroma formation and higher blood viscosity in chronic smokers [11].

Tobacco-use results in both health hazards and economic costs, that is large and growing $[12,13]$. Due to its easy accessibility and social acceptability, there are now more young women and teenagers having access to cigarettes and hence getting addicted. Its losses are uncountable. Some losses are directly related and some related indirectly. Smoking affects individual smoker, his or her family and society as a whole. Significant costs are being used for medicine purpose. It reduces the strength of individuals working capacity. As tobacco smoking is becoming a threat of the health of population and an economic burden, use of tobacco is not stopped and no anti-smoking efforts are made in Bangladesh [14]. Therefore, the relationship between smoking and the risk of ischemic stroke in the population of Bangladesh is to asses. Thus the purpose of the present study was to estimate the risk of smoking with ischemic stroke.

\section{Methodology}

This case control study was carried out in the Department of Biochemistry at Dhaka Medical College, Dhaka, Bangladesh from January 2014 to December 2014. Ethical clearance from the concerned departments and authorities was taken. A total number of 100 study subjects were taken of which 50 subjects presented with ischemic stroke were considered as case and the rest age and sex matched 50 healthy volunteers were taken as control. Cases were the patients who clinically suffered from ischemic stroke confirmed by computerized tomography (CT) scan of brain attending in the Medicine unit of Dhaka Medical College Hospital, during the study period. Apreformed data collection sheet was used to collect information regarding age, family history of stroke, history of hypertension and diabetes mellitus, smoking history with duration, relevant drug history, the height and weight of individuals to calculate Body Mass Index (BMI). Then, mean values of the quantitative variables were compared between case and control by Student's [ $t$-test] and expressed as mean \pm SD. Categorical variables were analyzed by using Chi square test. Finally, results were analyzed statistically in SPSS version 20. For all statistical analysis, $\mathrm{p}$ value $<0.05$ was considered as significant.

\section{Results}

A total number of 100 subjects were recruited for this study of which 50 ischemic stroke patients were considered as cases and the rest 50 were taken as healthy controls. In this study, there was no statistically significant difference of mean age between two groups $(p=0.124)$. The mean \pm SD of BMI was significantly higher in cases than that of controls $(\mathrm{p}=0.002)$, (Table 1).
Table 1. Demographic Characteristics of the Subjects.

\begin{tabular}{llll}
\hline Variables & Case $($ mean+SD) & Control (mean+SD) & P value \\
\hline Age $($ years $)$ & $56.54 \pm 12.18$ & $53.34 \pm 7.98$ & $0.124^{*}$ \\
BMI $\left(\mathrm{Kg} / \mathrm{m}^{2}\right)$ & $27.25 \pm 3.25$ & $25.38 \pm 2.57$ & $0.002^{*}$ \\
\hline
\end{tabular}

*Significance $(\mathrm{p}<0.05)$

Males were predominant in both case and control group. The gender difference between case and control was not statistically significant $(\mathrm{p}=0.414)$ (Table 2$)$.

Table 2. Gender Difference of Study Population.

\begin{tabular}{lllll}
\hline Sex & Case & Control & Total & P value \\
\hline Male & $32(64 \%)$ & $28(56 \%)$ & $60(60.0 \%)$ & \\
Female & $18(36 \%)$ & $22(44 \%)$ & $40(40.0 \%)$ & $0.414 * *$ \\
Total & $50(100.0 \%)$ & $50(100.0 \%)$ & $100(100.0 \%)$ & \\
\hline
\end{tabular}

$* *$ Chi square test was done to measure the level of significance $(\mathrm{p}<0.05)$

In this study, $42 \%$ patients of case group and $11 \%$ respondents of control group were smoker. Statistically significant difference was observed between two groups regarding the habit of smoking $(\mathrm{p}=0.032)$. Here, $\mathrm{OR}=2.56$ (95\%CI 1.0718 to 6.1501), risk of ischemic stroke is 2.56 times more in smokers than non-smokers (Table 3).

Table 3. Distribution of study subjects by smoking habit.

\begin{tabular}{lllll}
\hline Smoker & Case & Control & Total & P value \\
\hline Yes & $21(42.0)$ & $11(22.0)$ & $32(32.0 \%)$ & \\
No & $29(58.0)$ & $39(78.0)$ & $68(68.0 \%)$ & $0.032 *$ \\
Total & $50(100.0 \%)$ & $50(100.0 \%)$ & $100(100.0 \%)$ & \\
\hline
\end{tabular}

*Chi square test was done to measure the level of significance $(\mathrm{p}<0.05)$.

In case group, mean duration of smoking was $22.14 \pm$ 10.58 years and in control groups it were $4.45 \pm 2.58$ years. Statistically significant difference was observed between two groups regarding the duration of smoking $(\mathrm{p}=0.001)$ (Table 3).

Table 4. Distribution of study subjects by meanduration of smoking.

\begin{tabular}{llll}
\hline $\begin{array}{l}\text { Duration of } \\
\text { Smoking }\end{array}$ & $\begin{array}{l}\text { Case } \\
\text { (mean+SD) }\end{array}$ & $\begin{array}{l}\text { Control } \\
\text { (mean+SD) }\end{array}$ & P value \\
\hline $\begin{array}{l}\text { Mean duration of } \\
\text { smoking (yrs) }\end{array}$ & $22.14 \pm 10.58$ & $4.45 \pm 2.58$ & $<0.001$ \\
\hline
\end{tabular}

**Chi square test was done to measure the level of significance; Significance $=(\mathrm{p}<0.05)$.

\section{Discussion}

In the present study an association of smoking with ischemic stroke has been studied in Bangladeshi population at a tertiary care hospital. In this study, the mean age of the case and control groups are nearly similar this indicates that the two groups are in nearest age with more or less similar SD. Furthermore, the SD is also narrow. Thus this shows the two groups study population is age matched. Another study done by Abu-Odah et al [15] in European Gaza Hospital, revealed that the mean age of cases were 54.74 years and that of controls were 53.22 years. Statistically no significant $(\mathrm{p}=$ 
0.279) difference was found between case and control groups.

Among the study subjects, male: female ratio in case: 1.8 : 1; male: female ratio in control: $1.3: 1$; the sex of case and control were matched. In most age groups except older adults, stroke is more common in men than women. Stroke incidence rate is 1.25 times greater in men. But because of longer life span of women, more women than men die of stroke each year [11]. In Bangladesh, females in comparison to males are more neglected due to low socioeconomic condition. Therefore, very few number of female stroke patients can reached to the hospital for better outcome than male.

Smoking is an important modifiable risk factor for ischemic stroke. Smoking appears to be involved in the pathogenesis of stroke via two mechanisms. First, smoking can cause direct damage to the vasculature, altering both its architecture and function. Second, smoking has effects on hemodynamic factors within the circulation [16].

Smoking nearly doubles the risk of ischemic stroke of an individual. Inhalation of tobacco smoke contains over 7,000 toxic chemicals including carbon monoxide, formaldehyde and hydrogen cyanide [17]. These chemicals are transferred from lungs to bloodstream and causes changes and damaging of cells all around the body and thereby increases the stoke risk. Smoking also reduces the HDL-C level and increases the bad cholesterol (LDL-cholesterol) level in blood and increase smoker's risk of developing atherosclerosis [17]. Smoking is believed to induce the development of atherosclerosis by initiating endothelial injury due to either the production of oxygen radicals or via direct toxic effects of cigarette smoke constituents. Even brief exposure to cigarette smoke has been found to activate leukocytes, stimulating the release of the pro-coagulant, von Willebrand Factor (vWF) and causing endothelial damage [18].

Smoking is a higher risk factor of developing cerebral ischaemic events in two ways. First, due to a reduced ability to respond to alteration in perfusion pressure, and second, due to lack of distensibility of the arterial wall as a result of endothelial dysfunction. Kool et al [19] found that blood pressure and heart rate were significantly increased following smoking, whereas carotid artery distensibility was significantly decreased. It was postulated that the increased wall stiffness, blood pressure and heart rate could cause an increase in load on the vessel wall, which could lead to plaque rupture and acute ischemic events. This is particularly relevant in light of evidence that smokers have increased levels of atherosclerosis.

Smoking causes increased fibrinogen level and platelet adhesiveness and reduced cerebral blood flow mainly due to atheroma formation and higher blood viscosity in chronic smokers [11]. The more one smokes, the more increases the stroke risk. If a person smokes 20 cigarettes per day, risk of developing ischemic stroke is six times more than nonsmoker [17]. Major risk is reduced within 2 to 4 years after cessation of smoking. This reduction in risk occurs throughout all age spans and in heavy as well as in moderate smokers [11].

The result of the current study showed that $42.0 \%$ cases of ischemic stroke and $11 \%$ respondents of control group were smoker. Significant difference was observed between two groups regarding smoking habit $(\mathrm{p}=0.032)$. Another study done by Kirtania et al [20], in Bangladesh revealed that $56.66 \%$ patients of case group and $53.33 \%$ volunteers of control group were smoker. But there was no statistically significant difference was observed regarding smoking habit.

In the current study among cases, mean duration of smoking was $22.14 \pm 10.58$ years and in control group, $4.45 \pm 2.58$ years respectively. Statistically highly significant difference was observed between two groups regarding the duration of smoking $(p=<0.001)$. Another study done by Jalaluddin et al [21], in Bangladeshi population revealed that duration of smoking is significantly longer $(p<0.01)$ in ischemic stroke patients $(35.26 \pm 9.97$ years $)$ than the control group (24.12 \pm 7.32 years).

\section{Conclusion}

In conclusion, prolong duration of smoking are significantly associated with ischemic stroke. Therefore, this study suggests that smoker subjects should give up smoking immediately to reduce the risk of developing stroke. Prevention still remains the most effective way of reducing the impact of stroke.

\section{References}

[1] Rajput MR, Lakhair MA, Shaikh MA, Rind MS, Bano R. CReactive Protein (CRP) and other risk factors in acute ischemic stroke patients. JLUMHS 2011; 10 (3): 131-133.

[2] Kaur J, Prabhu KM, Thakur LC. Serum magnesium levels in ischemic cerebrovascular disorders: a case- control pilot study in north Indian population. JPBMS 2012; 17: 1-4.

[3] Darvishi L, Hariri M, Hajishafiei M, Ghasemi S, Maghsoudi Z, Askari G, et al. Comparison of fat intake between patients with stroke and normal population. J Res Med Sci 2013; 18(1): $1-50$.

[4] Donnan GA, Fisher M, Macleod M, Davis SM. Stroke. Lancet 2008; 371:1612-1623.

[5] Jauch EC. Ischemic stroke [Internet]. 2014 [updated 2015 Jan 20; cited 2014 Sep 10]. Available from: http://emedicine.medscape.com/article/1916852overview\#a0156

[6] MacMahon S, Rodgers A. The epidemiological association between blood pressure and stroke: implications for primary and secondary prevention. Hypertension Res 1994; 17: S23S32.

[7] $\mathrm{Ng} \mathrm{M}$, Freeman MK, Robinson M, Dwyer-Lindgren L. Smoking prevention and cigarette consumption in 187 countries, 1980-2012. JAMA 2014; 311: 183-92.

[8] World Health Organization, 2014. WHO report on the global tobacco epidemic. 
[9] Alam DS, Jha P, Ramasundarahettige C, Streatfield PK, Niessen LW Smoking attributable mortality in Bangladesh: proportional mortality study. Bull World Health Organ 2013; 91: 757-64.

[10] Summary Health Statistics for U.S. Adults: National Health $\begin{array}{llll}\text { Interview } & \text { Survey, } & 2008 . & \text { p. }\end{array}$ www.cdc.gov/nchs/data/series/sr_10/sr10_242.pdf.

[11] Sacco RL, Benjamin EJ, Broderick JP, Dyken M, Easton JD, Feinberg WM, et al. Risk factors: stroke. Stroke. Am Stroke Asso J 1997; 28: 1507-1517.

[12] Wu F, Chen Y, Parvez F, Segers S, Argos M. A prospective study of tobacco smoking and mortality in Bangladesh. PLOS one 2013 ;(8) 2013; e58516.

[13] Nargis N, Ruthbah UH, Hussain AK, Fong GT, Huq I. The price sensitivity of cigarette consumption in Bangladesh: evidence from the international tobacco control (ITC), Bangladesh Wave 1 (2009) and Wave 2 (2010) surveys, Too control 23 suppl(1) 2014; i39-47.

[14] Sultana P, Akter S, Rahman MM, Alam MS. Prevalence and predictors of current tobacco smoking in Bangladesh. J Biostatistics Biometric Applications 2015; 1(1): 1-8.

[15] Abu-Odah H, Abed Y, Abu-Hamad B. Risk Factors of Stroke in Patients Admitted in European Gaza Hospital, Gaza Strip: A case Control Study in Medical Unit Setting. J Neurol Disord Stroke 2014; 2(4): 1-5.

[16] Seana L, Amanda G, Thrift, Geoffrey A. Smoking as a Crucial Independent Determinant of Stroke. Tobacco Induced Dis 2004;2 (2): 67-80.

[17] Smoking and the risk of stroke. 2012. Available from: www.stroke.org.uk

[18] Blann AD, Kirkpatrick U, Devine C, Naser S, McCollum CN. The influence of acute smoking on leucocytes, platelets and the endothelium. Atherosclerosis 1998; 141: 133-139.

[19] Kool MJ, Hoeks AP, Struijker-Boudier HA, RenemanRS, Bortel V. Short- and long-term effects of smoking on arterial wall properties in habitual smokers. J Am Coll Cardiol 1993; 22: $1881-1886$.

[20] Kirtania K, Sultana N, Ahmed S, Khatun A. Association of hypertension and smoking with ischemic stroke. Bangladesh J Med Biochem 2010;3(1): 16-18.

[21] Jalaluddin MD, Mondol BA, Ahmed S, Anwarullah AKM, Jabbar MA, Mohammad QD. Smoking and ischemic stroke. Bangladesh J Neurosci 2008; 24(1):50-54. 